\begin{tabular}{|c|c|c|}
\hline $\begin{array}{l}\text { PKS } \\
\text { PUBLIC } \\
\text { KNOWLEDGE } \\
\text { PROJECT }\end{array}$ & $\begin{array}{c}\text { Revista de GEOGRAFIA } \\
\text { (RECIFE) } \\
\text { http://www.revistauffe.br/revistageografia }\end{array}$ & $\begin{array}{l}\text { OJS } \\
\frac{\text { OJEN }}{\text { OPENAL }} \\
\text { SYSTEMS }\end{array}$ \\
\hline
\end{tabular}

\title{
GEOPARQUE SERIDÓ (RN) E SUAS FEIÇÕES GEOMORFOLÓGICAS
}

\author{
Marcos Antonio Leite do Nascimento ${ }^{1}$ \\ ${ }^{1}$ Departamento de Geologia, Pós-Graduação em Geodinâmica e Geofísica, Pós-Graduação em Turismo, UFRN. \\ Email:marcos@geologia.ufrn.br
}

Artigo recebido em 17/07/2018 e aceito em 18/08/2018

\begin{abstract}
RESUMO
O relevo terrestre se encontra em constantes mudanças ao longo do tempo, mostrando-se com diferentes feições e parte dessas são encontradas no território do Geoparque Seridó/RN. No RN identificou-se que dos sete domínios geomorfológicos descritos (i) Planícies Costeiras; (ii) Vales dos rios Piranhas e Apodi; (iii) Tabuleiros Costeiros; (iv) Baixos Platôs da Bacia Potiguar; (v) Planaltos Residuais Sertanejos; (vi) Planaltos da Borborema e (vii) Depressão Sertaneja; três estão inseridos no território do geoparque, são eles: Planaltos Residuais Sertanejos; Planaltos da Borborema e Depressão Sertaneja. Dos dezessete padrões de relevo mapeados, sete foram identificados (i) planaltos; (ii) chapadas e platôs; (iii) superfícies aplainadas retocadas ou degradas; (iv) inselbergs e outros relevos residuais; (v) domínio de colinas dissecadas e de morros baixos; (vi) domínio de morros e serras baixas; e (vii) escarpas serranas. No mapeamento geomorfológico apenas uma das quatro unidades morfoestruturais foi identificada, o Cinturão Orogênico Brasiliano. Das sete unidades morfoesculturais, somente duas estão no território (i) Depressão Sertaneja e (ii) Planalto da Borborema. As diferentes geoformas encontradas, como as pedras do Caju, do Dinossauro, do Nariz e do Coração permitem aos visitantes não apenas contemplar a paisagem natural em si, mas também se aproximar de conhecimentos ainda não adquiridos em outros momentos.
\end{abstract}

Palavras-chaves: Geomorfologia, Seridó, Geoparque.

\section{SERIDÓ GEOPARK AND ITS GEOMORPHOLOGICAL FEATURES}

\begin{abstract}
The terrain relief is in constant changes over time, showing itself with different features and some of these are found in the territory of the Serido Geopark/RN. In the RN it was identified that of the seven geomorphological domains described (i) Coastal Plains; (ii) Valleys of the Piranhas and Apodi rivers; (iii) Coastal Boards; (iv) Low Plateaus of the Potiguar Basin; (v) Sertanejo Residual Plateaus; (vi) Borborema Plateaus and (vii) Sertaneja Depression; three are inserted in the territory of the geopark, they are: Sertanejo Residual Plateaus; Borborema Plateaus and Sertaneja Depression. Of the seventeen mapped relief patterns, seven were identified (i) plateaus; (ii) plated and plateaus; (iii) flattened surfaces retouched or degraded; (iv) inselbergs and other residual reliefs; (v) domain of dissected hills and low hills; (vi) domain of hills and low hills; and (vii) mountain escarpments. In the geomorphological mapping only one of the four morphostructural units was identified, the Brasilian Orogenic Belt. Of the seven morphoscultural units, only two are in the territory (i) Sertaneja Depression and (ii) the Borborema Plateau. The different geoforms found, such as the Cashew, Dinosaur, Nose and Heart stones allow visitors not only to contemplate the natural landscape itself, but also to approach knowledge not yet acquired at other times.
\end{abstract}

Keywords: Geomorphology, Seridó, Geopark. 


\section{INTRODUÇÃO}

O relevo da Terra passa por constantes transformações ao longo do tempo, onde processos endógenos e exógenos esculpem diferentes modelados. Por se encontrar sobre a camada superficial da Terra é fácil perceber que o relevo terrestre se mostra com diferentes fisionomias, algumas mais elevadas, outras mais baixas, umas mais acidentadas, outras mais planas. Assim sendo, avaliar essas formas de relevo permite com que elas possam ser utilizadas na educação, servindo como palco para estudos em diferentes níveis do ensino ou sendo úteis na definição de áreas atrativas para o uso turístico.

Na porção centro-sul do Estado do Rio Grande do Norte, conhecida como Seridó, o relevo se encontra com diferentes formas e compreender como, porque e quando elas se formaram é de suma importância para a conservação e o uso dessas formas, muitas únicas e particulares. Desta forma, com a chegada do Geoparque Seridó, tais informações estão sendo obtidas com o objetivo de levar esse conhecimento à sociedade e assim permitir com que ela faça parte dessa história que teve início a milhares de anos atrás. Sem falar que se formos pensar na história das rochas que compõem essas diferentes formas de relevo estaríamos falando de bilhões de anos.

Assim, o presente trabalho tem como objetivo central apresentar as principais características geomorfológicas do território que compõe o Geoparque Seridó, com base em publicações já existentes para o Estado do Rio Grande do Norte, lançando mão de trabalhos realizados em diferentes escalas e aspectos.

\section{MATERIAIS E MÉTODOS}

Os procedimentos metodológicos desenvolvidos para a realização deste trabalho envolveu os levantamentos cartográfico e bibliográfico relacionando à temática em estudo, com especial destaque aos trabalhos de mapeamentos geomorfológicos já realizados no território do Geoparque Seridó; e identificação e contextualização da área, com observação in loco das diferentes feições do relevo e dos aspectos geológicos, com registro fotográfico das principais características da paisagem. 


\section{O PROJETO GEOPARQUE SERIDÓ}

O projeto Geoparque Seridó localiza-se na porção centro-sul do Estado do Rio Grande do Norte e compreende um estudo técnico que serviu como base inicial para a inventariação de 16 geossítios contendo valores científico, educativo e turístico (MEDEIROS et al. 2017), situados nos municípios de Cerro Corá (geossítios Serra Verde, Cruzeiro de Cerro Cora e Vale Vulcânico); Lagoa Nova (Mirante de Santa Rita); Currais Novos (Pico do Totoró, Morro do Cruzeiro, Mina Brejuí, Cânions dos Apertados); Acari (Gargalheiras, Poço de Arroz, Cruzeiro de Acari e Marmita do Rio Carnaúba); Carnaúba dos Dantas (Xiquexique e Monte do Galo); Parelhas (Açude Boqueirão e Mirador).

O Seridó potiguar apresenta um dos mais completos e belos patrimônios geológicos encontrados no Nordeste, o qual é decorrente de inúmeros processos naturais a que esta região foi submetida ao longo do Tempo Geológico. Tendo em vista o caráter excepcional deste patrimônio geológico, associado ao aspecto cultural da região, a área proposta atende as necessidades para criação do Geoparque Seridó.

O portão de entrada do geoparque, para quem vem de Natal, pode ser considerado a cidade de Currais Novos que está a $172 \mathrm{~km}$ da capital potiguar. Parelhas é dentre as cidades da região do Seridó, a mais afastada da capital, distando $232 \mathrm{~km}$. Já a distância entre os municípios situados em pontos extremos do referido geoparque não ultrapassa os $100 \mathrm{~km}$, como é o caso de Cerro Corá (extremo norte da área) até Parelhas (extremo sul).

A soma das áreas que envolvem os 6 municípios do Geoparque Seridó totaliza 2.802 $\mathrm{km}^{2}$ (Figura 1) e para uma região que apresenta médios índices de desenvolvimento humano (variação de 0 a 1), população relativamente numerosa e carente de recursos, a implantação de um projeto de desenvolvimento territorial sustentável, como é o caso de um geoparque, seria mais uma alternativa de geração de renda. 
Figura 1 - Mapa de localização dos geossítos no Geoparque Seridó.

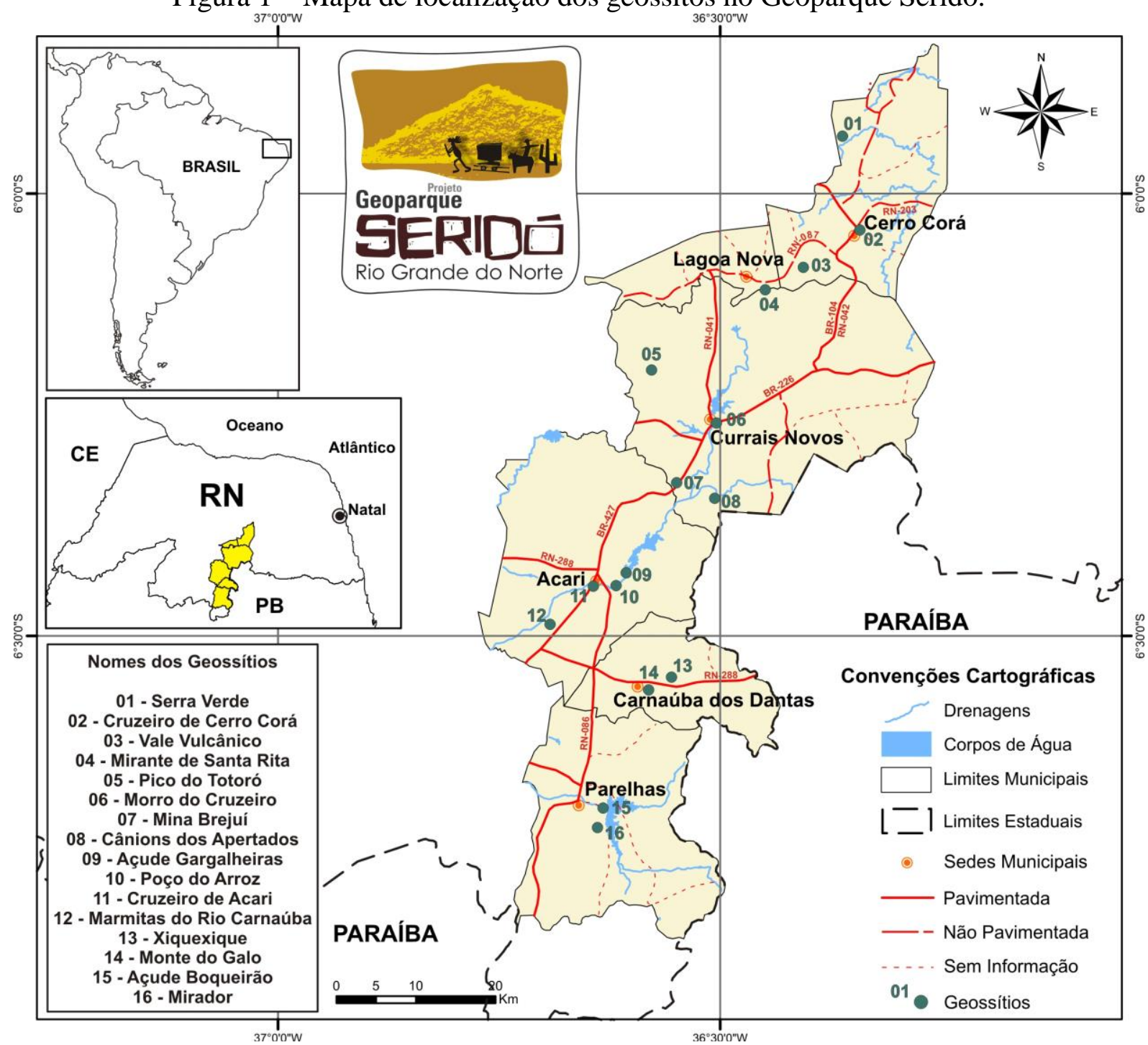

Fonte: o autor.

\section{FEIÇÕES GEOLÓGICAS DO GEOPARQUE SERIDÓ}

O território do Geoparque Seridó é formado geologicamente por um embasamento composto por ortognaisses e augen gnaisses paleoproterozoicos correlacionados ao Complexo Caicó, além de augen gnaisses paleoproterozoicos associados a Suíte Poço da Cruz (Figura 2). 


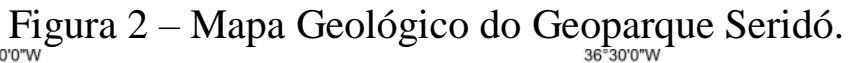

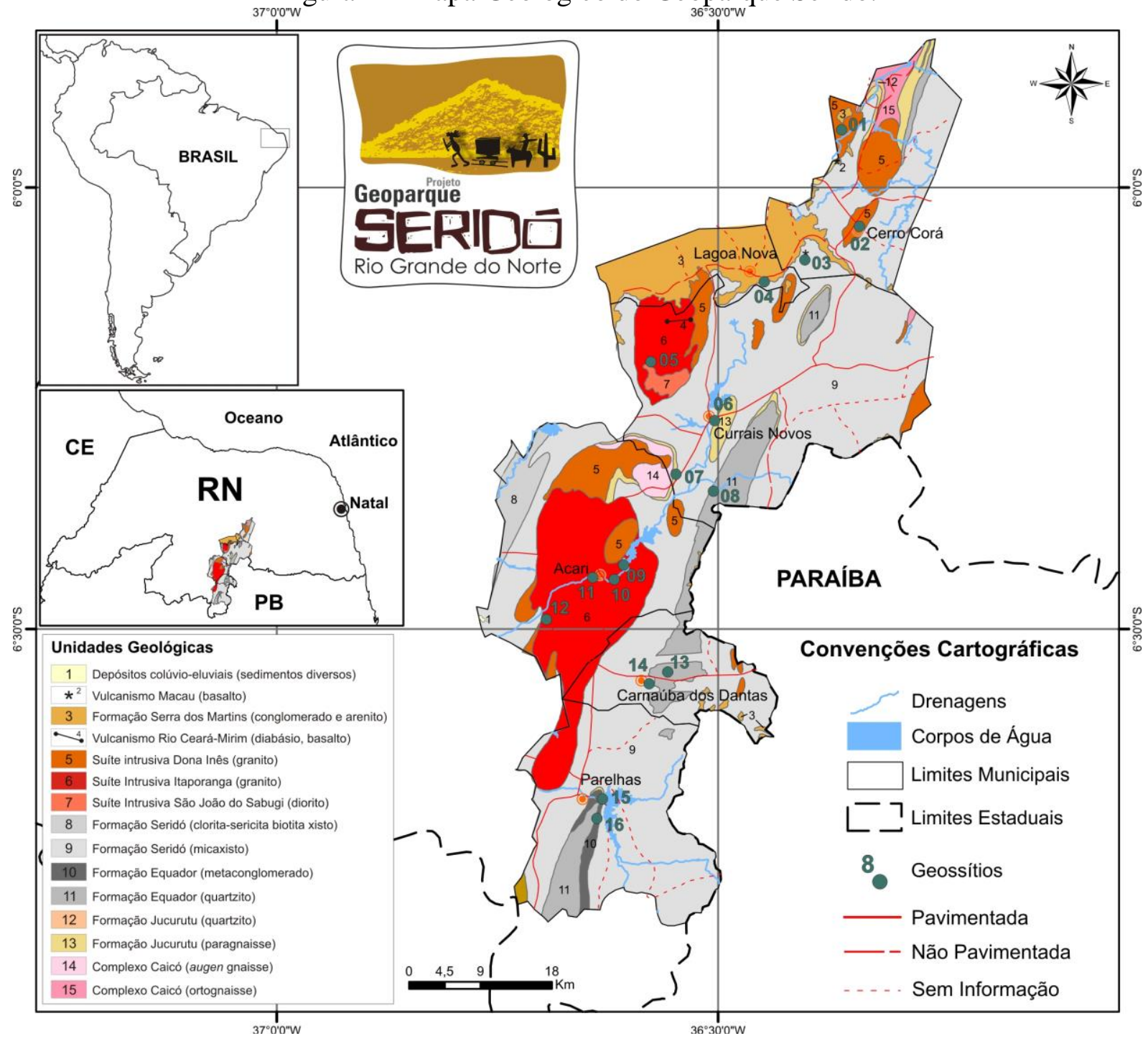

Fonte: o autor.

Posicionado de forma discordante sobre essas rochas do embasamento cristalino ocorrem rochas metassedimentares do Grupo Seridó, formada por uma sequência neoproterozoica, compostas na base por paragnaisses, quartzitos e mármores da Formação Jucurutu, no meio por quartzitos e metaconglomerados da Formação Equador, e no topo, por micaxistos da Formação Seridó.

Afetando todas essas rochas ocorrem diferentes tipos de granitoides, com destaque para as suítes intrusivas Dona Inês (granitos equigranulares de granulometria fina e cor rósea a cinza) e Itaporanga (granitos inequigranulares, de granulometria grossa, com fenocristais de K-feldspato, de cor rósea), além de dioritos/gabros (equigranulares de granulometria fina, de cor preta a verde) da Suíte Intrusiva São João do Sabugi, todas de idade neoproterozoica. O magmatismo meso-cenozóico está representado no território por diabásio do Vulcanismo Rio- 
Ceará-Mirim e basaltos do Vulcanismo de Macau. Finalmente, os conglomerados e os arenitos da Formação Serra do Martins constituem a cobertura cenozóica da área.

\section{FEIÇÕES GEOMORFOLÓGICAS DO GEOPARQUE SERIDÓ}

\section{O Geoparque Seridó no Mapa de Domínios Geomorfológicos do Rio Grande do Norte}

Dantas e Ferreira (2010) tomaram como base a classificação dos domínios morfoclimáticos do Brasil (AB'SABER, 1969), para definir o relevo do Rio Grande do Norte. Este relevo encontra-se inserido em dois domínios e uma faixa de transição, descritos como (i) Domínio de Mares de Morros correspondendo aos Tabuleiros Costeiros do Nordeste Oriental; (ii) Domínio das Depressões Intermontanas e Interplanálticas das Caatingas, que é formado por quatro conjuntos de feições morfológicas principais: superfícies de aplainamento da Depressão Sertaneja; chapadas sustentadas por rochas sedimentares; serras isoladas; e Planalto da Borborema; e intercalando esses dois domínios, existe uma importante (iii) faixa de transição morfoclimática, do litoral úmido para o sertão semi-árido, denominado Agreste Potiguar.

Tomando como base a análise dos produtos de sensoriamento remoto disponíveis, perfis de campo e estudos geomorfológicos regionais anteriores (IBGE, 1995; ROSS, 1985, 1997), Dantas e Ferreira (2010) definiram para o estado do Rio Grande do Norte sete domínios geomorfológicos, descritos como Planícies Costeiras; Vales dos rios Piranhas e Apodi; Tabuleiros Costeiros; Baixos Platôs da Bacia Potiguar; Planaltos Residuais Sertanejos; Planaltos da Borborema e Depressão Sertaneja, com esses três últimos inseridos no Geoparque Seridó (Figura 3). 
Figura 3 - Mapa de Domínios Geomorfológicos do Rio Grande do Norte.

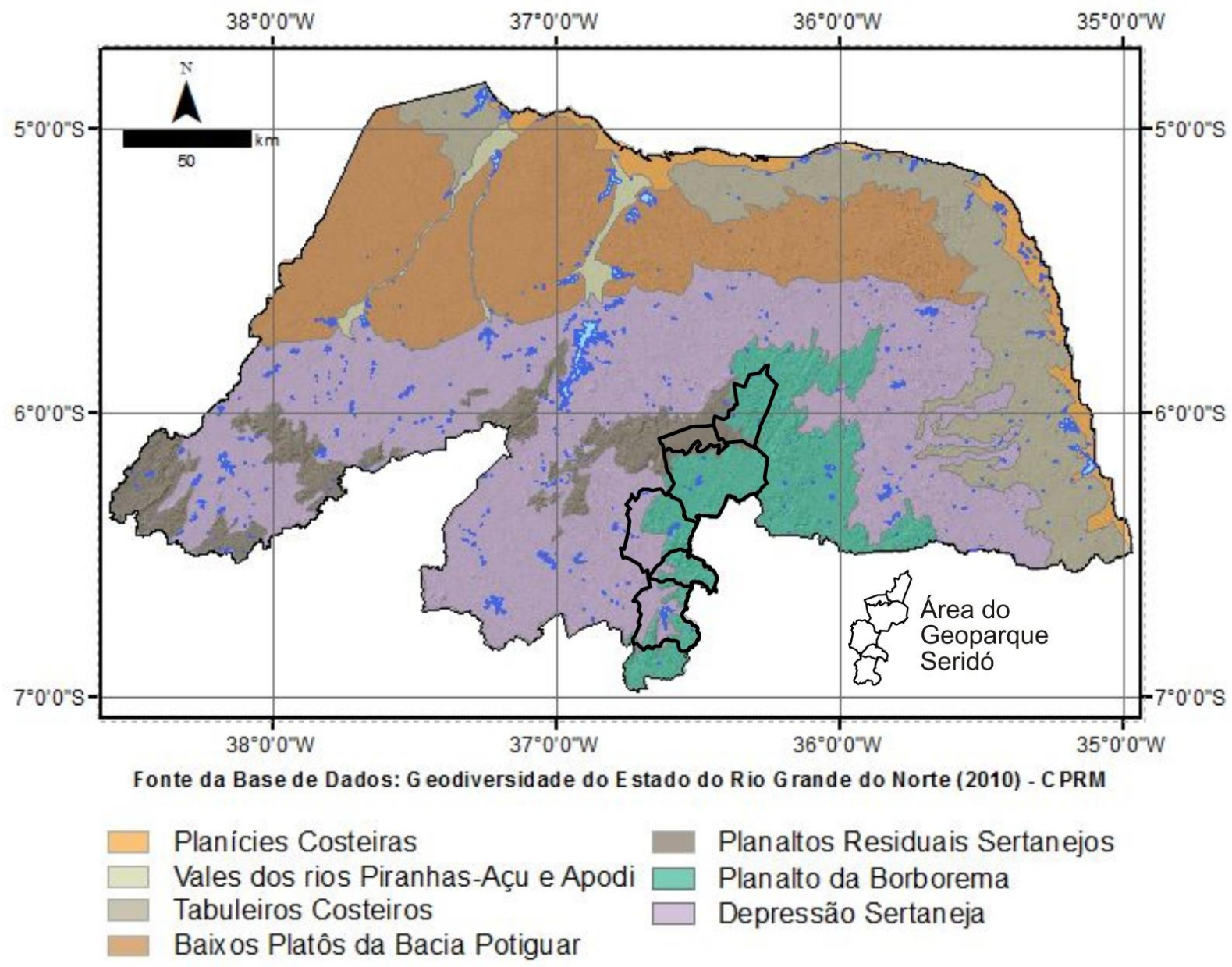

Fonte: Dantas e Ferreira (2010).

\section{O Geoparque Seridó no Mapa de Padrões de Relevo do Rio Grande do Norte}

Diversos padrões de relevo podem ser caracterizados nos domínios apresentados anteriormente, como explicam Dantas e Ferreira (2010). Esses autores apresentam os diversos padrões de relevo do estado do Rio Grande do Norte, totalizando dezessete (Figura 4), que estão inseridos nos domínios morfoclimáticos. 
Figura 4 - Mapa de Padrões de Relevo do Rio Grande do Norte.

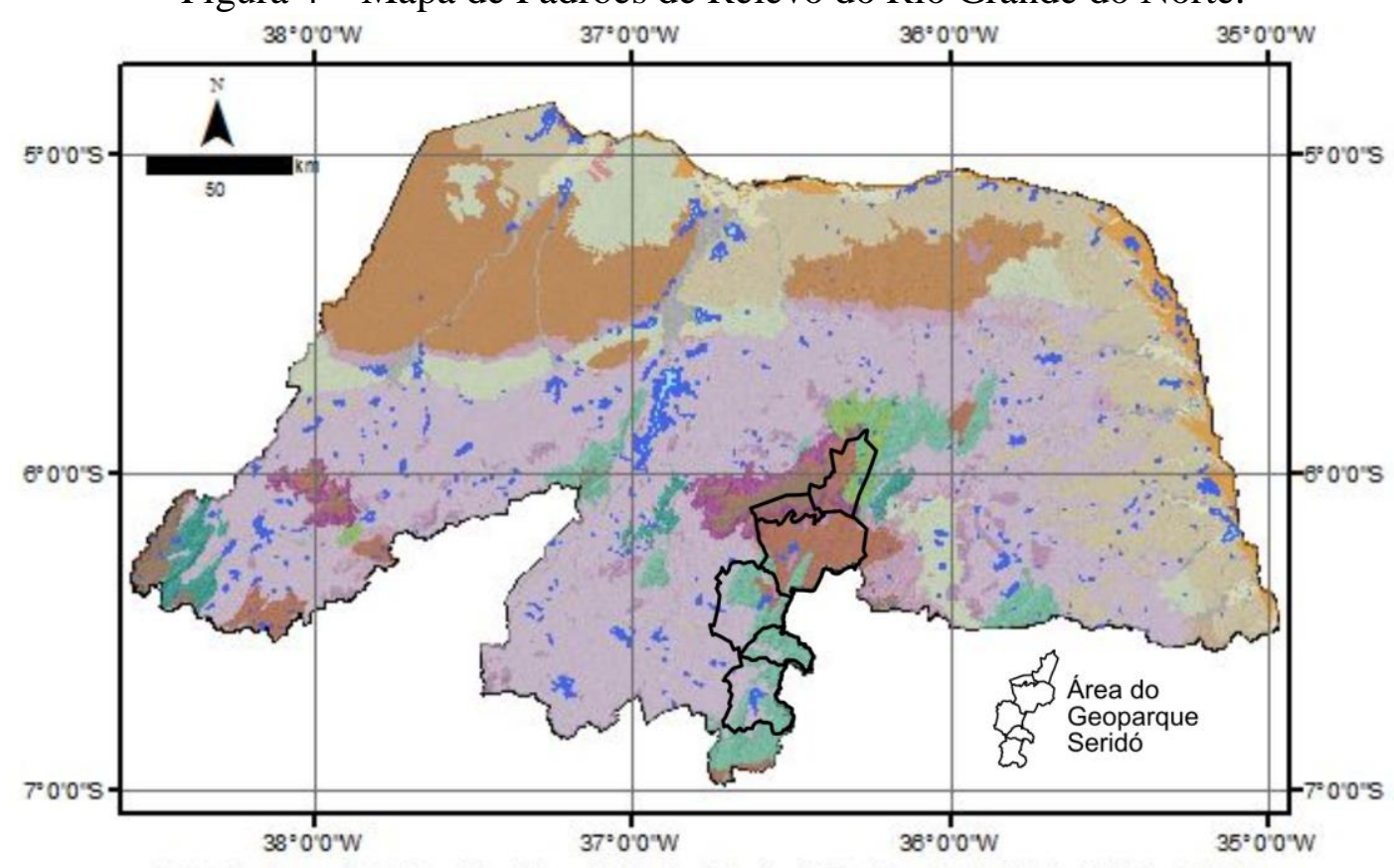

Fonte da Base de Dados: Geodiversidade do Estado do Rio Grande do Norte (2010) - CPRM

Planícies fluviais e fluviolacustre

Vertentes recobertas por depósitos de encosta

Planícies flúvio-marinhas e fluvio-lagunares

Campos de dunas

Tabuleiros

Tabuleiros dissecados

Baixos platôs

Planaltos

Chapadas e platôs
Superficies aplainadas recortadas Inselbergs e outros relevos residuais Dominio de colinas amplas e suaves Domínio de colinas dissecadas e morros baixos Domínios de morros e serras baixas Domínio montanhoso Escarpas serranas

Degraus estruturais e rebordos erosivos

Fonte: Dantas e Ferreira (2010).

A individualização dos diversos padrões de relevo foi obtida tendo como base a análise de imagens SRTM (Shuttle Radar Topography Mission), possuindo resolução de 90 $\mathrm{m}$, além de imagens GeoCover, sendo agrupadas as unidades de relevo de acordo com a análise da textura e rugosidade das imagens. A escala final de trabalho foi a de 1:500.000.

As feições de relevo regionais presentes no território do Geoparque Seridó estão contidas no Domínio das Depressões Intermontanas e Interplanálticas das Caatingas, sendo encontrados naquele território sete padrões de relevo, que estão representados no Mapa de Padrões de Relevo do Geoparque Seridó (Figura 5). Os padrões de relevos encontrados estão descritos a seguir.

As superfícies aplainadas degradadas (R2a2) compreendem um conjunto de padrões de relevos planos e suavemente ondulados, resultante de processos de arrasamento generalizado do modelado sobre diversos tipos de litologias, sendo a unidade de maior extensão na área do geoparque. Estas vastas superfícies aplainadas encontram-se pontilhadas 
por inselbergs (R3b), que aparecem na paisagem como montes isolados, elevando-se, em muitos casos, centenas de metros acima do piso da superfície regional.

$\mathrm{Na}$ região leste, onde o geoparque faz fronteira com o estado da Paraíba, encontra-se um conjunto de morros e serras baixas (R4b, Figura 6a), com desníveis inferiores a $300 \mathrm{~m}$, que junto com a morfologia planáltica (R2b3, Figura 6b), mais ao norte, constituem parte do rebordo norte do Planalto da Borborema, representando relevos residuais remanescentes daquele planalto. Em contato com o relevo planáltico, encontra-se a imponente escarpa da Serra de Santana, que representa um relevo de transição entre superfícies distintas alçadas a diferentes cotas altimétricas, apresentando desnivelamento em torno de 400 metros e com deposição de rampas de colúvio e depósitos de tálus na base da escarpa (R4d). A Serra de Santana consiste num platô (R2c, Figura 6c), que representa fragmento de uma pretérita superfície de cimeira capeada por arenitos laterizados de idade Neógena da Formação Serra do Martins, com cotas chegando a 750 metros de altitude.

No extremo NE da área do geoparque, encontra-se no limiar do domínio planáltico um conjunto de colinas dissecadas (R4a2, Figura 6d), com vertentes convexo-côncavas e topos aguçados, com variação de cotas altimétricas entre 30 e 80 metros, em relação ao piso regional, onde por vezes se encontram campos de matacões, indicando uma predominância do intemperismo físico. 
Figura 5 - Mapa de Padrões de Relevo do Geoparque Seridó.

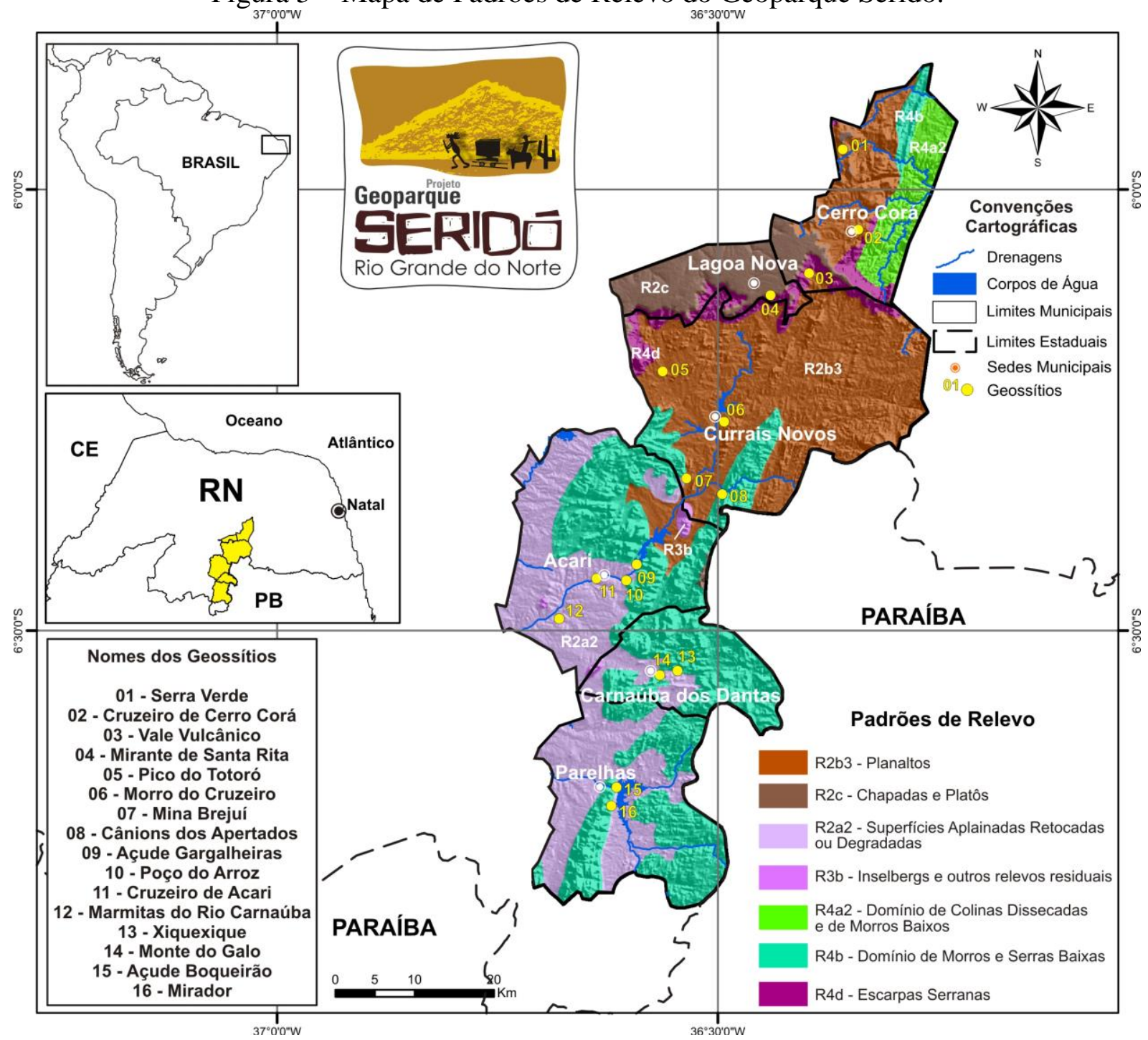

Fonte: o autor, com base em Dantas e Ferreira (2010). 
Figura 6 - Diferentes padrões de relevo definidos para o território do Geoparque Seridó, com destaque para (a) Domínio de Morro e Serras Baixas (R4b), (b) Planaltos (R2b3), (c) Chapadas e Platôs (R2c) e (d) Colinas Dissecadas (R4a2).
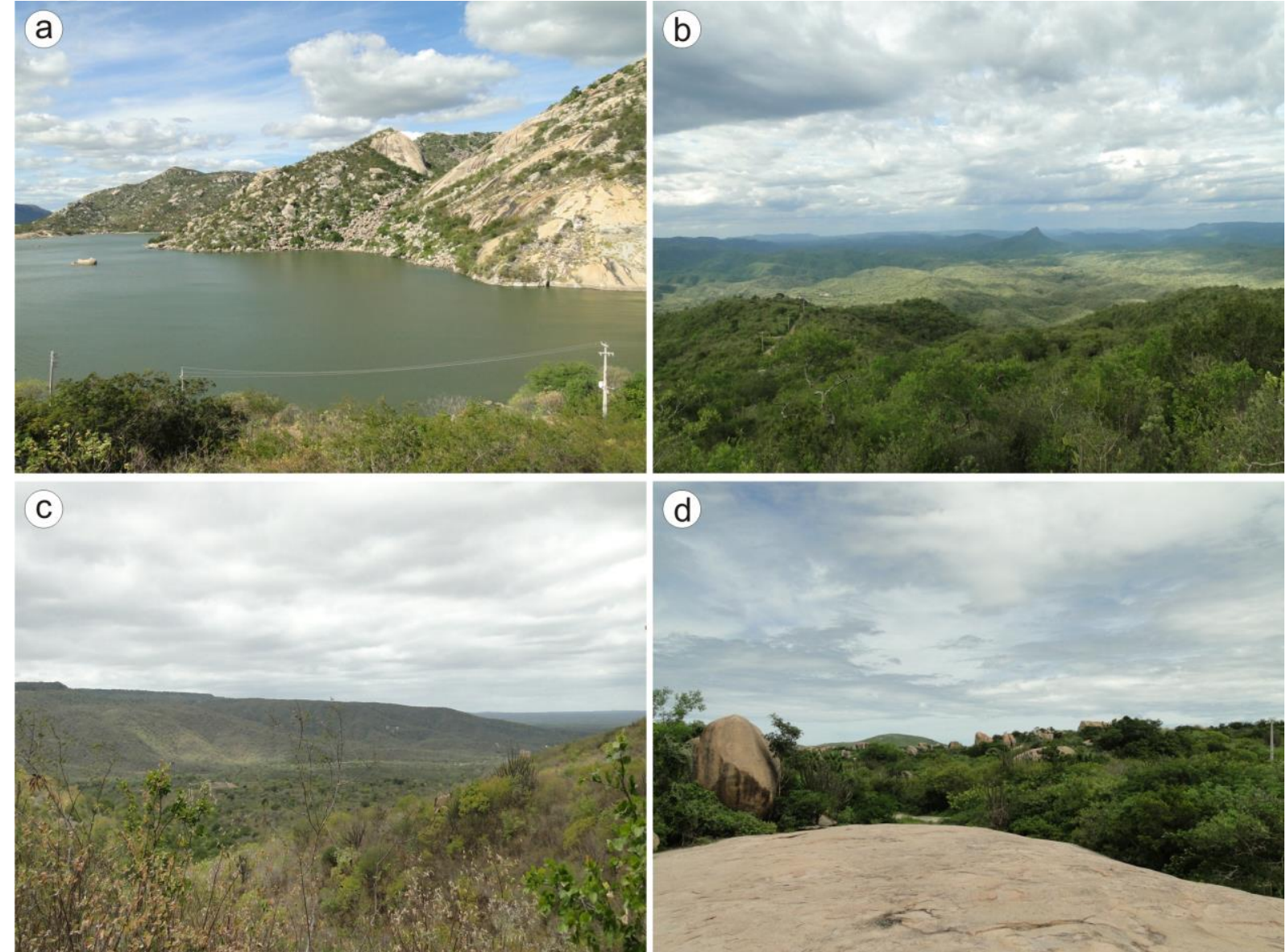

Fonte: (a) Marcos Nascimento, (b) Rogério Ferreira, (c) Marcos Nascimento, (d) Rogério Ferreira.

\section{O Geoparque Seridó no Mapa Geomorfológico do Rio Grande do Norte}

Diniz et al. (2017) publicaram o Mapa Geomorfológico do Estado do Rio Grande do Norte, na escala 1:250.000, lançando mão da metodologia de Ross (1992), com adaptações de Santos et al. (2006) para o estado do Paraná, com o objetivo principal de atualizar os conhecimentos da cartografia geomorfológica regional.

A escala adotada possibilitou utilizar três primeiros táxons, correspondendo a representação cartográfica das Unidades Morfoestruturais, Unidades Morfoesculturais e Subunidades Morfoesculturais. No primeiro taxon foram identificadas as unidades morfoestruturais, descritas como (i) Cinturão Orogênico Brasiliano; (ii) Bacias Sedimentares Marginais; (iii) Vulcanismo e/ou Plutonismo Cenozoico; e (iv) Coberturas Sedimentares Quaternárias. Para o segundo taxon foram identificadas as unidades morfoesculturais: (i) 
Depressão Sertaneja; (ii) Planalto da Borborema; (iii) Maciços e Planaltos Interiores; (iv) Planaltos e Tabuleiros Costeiros; (v) Relevos Tectônicos nas Bacias Marginais; (vi) Relevos Associados ao Vulcanismo/Plutonismo Neógeno; e (vii) Planícies Costeiras e Fluviais. Por fim, para o terceiro táxon foram encontradas trinta subunidades morfoesculturais (Figura 7).

Figura 7 - Mapa Geomorfológico do Rio Grande do Norte.

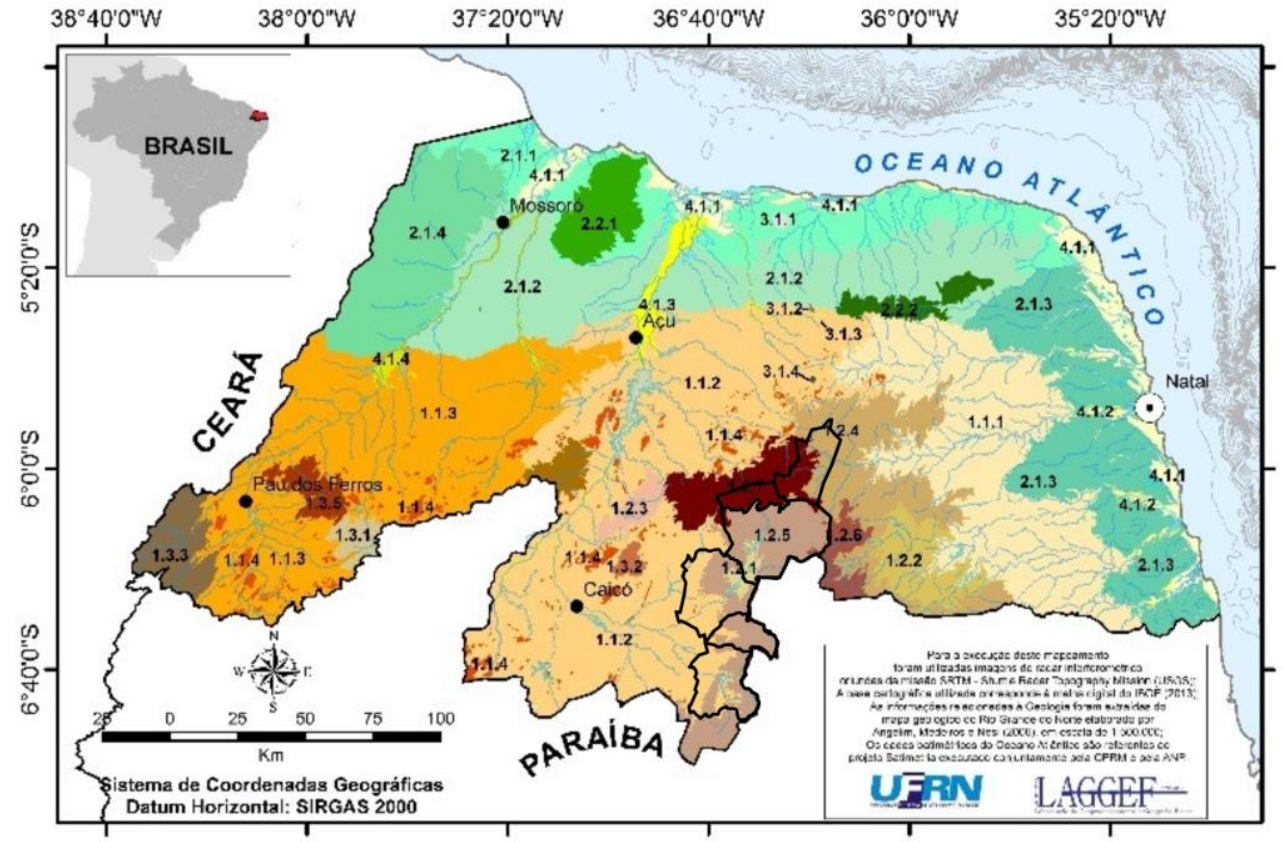

\section{LEGENDA}

UNIDADE MORFOESTRUTURAL: CINTURĀO OROGÉNICO BRASILIANO

UNIDADE MORFOESCULTURAL: DEPRESSĀO SERTANEJA Subunidades mortoesculturais

1.1.1 Depressão Interplanáltica Orienta

1.1.2 Depressāo Interplanaltica do Piranhas-Açu

1.1.3 Depressäo Interplanaltica do Apodi Mossoro

1.1.4 Inselbergs e Campos de Inselbergs

UNIDADE MORFOESCULTURAL: PLANALTO DA BORBOREMA Subunidades mortoesculturais

1.2.1 Depressāo Intraplanaltica do Acauả

1.2.2 Depressâo Intraplanáltica do Trairi

1.2.3 Compartimento Florânia

1.2.4 Compartimento Potengi-Trairi

1.2.5 Compartimento Seridó

1.2.6 Compartimento Monte das Gameleiras

Compartimento Serra de Santana

UNIDADE MORFOESCULTURAL:

MACICYOS E PLANALTOS INTERIORES

Subunidades morfoesculturais

1.3.1 Maciço do Culumim

1.3.2 Maciço da Formiga

1.3.3 Planalto do Pereiro

1.3.4 Planalto de Joáo do Vale

1.3.5 Planalto de Martins-Portalegre
UNIDADE MORFOESTRUTURAL: BACIAS SEDIMENTARES MARGINAIS

UNIDADE MORFOESCULTURAL: PLANALTOS E TABULEIROS COSTEIROS Subunidades morfoesculturais

2.1.1 Tabuleiros Costeiras Setentrionais

2.1.2 Tabuleiros Interiores

2.1.3 Tabuleiros Costeiros Dissecados 2.1.4 Chapada do Apodi

UNIDADE MORFOESCULTURAL: RELEVOS TECTONICOS NAS BACIAS MARGINAIS Subunidades morfoesculturais

2.2.1 Planalto da Serra do Me

2.2.2Planalto da Serra Verde

\section{UNIDADE MORFOESTRUTURAL:} PLUTONISMO CENOZÓICO

UNIDADE MORFOESCULTURAL: RELEVOS ASSOCIADOS AO
VULCANISMOIPLUTONISMO NEÓGENO Subunidades morfoesculturais

3.1.1 Domo do Mangue Seco

3.1.2 Plug Serra Preta de Pedro Avelino

3.1.3 Neck Serra Aguda

3.1.4 Pico (Neck) do Cabugi

Fonte: Diniz et al. (2017).
UNIDADE MORFOESTRUTURAL: COBERTURAS SEDIMENTARES QUATERNARIAS

UNIDADE MORFOESCULTURAL: PLANICIES COSTEIRAS E FLUVIAIS Subunidades morfoesculturais

4.1.1 Planícies Costeiras

4.1.2 Planícies do Litoral Oriental

4.1.3 Planicies Fluviais da Bacia do Piranahas-Aç 4.1.4 Planicie Fluviais da Bacia do Apodi-Mossoro

CONVENÇÖES CARTOGRÁFICAS

(.) Capital Estadual

- Cidades

- Drenagern

an Isobátas (profundidade em m)

— Limites Interestaduais do Brasil Corpos D'água

5 Área do

Geoparque Seridó 
O território do Geoparque Seridó contempla apenas uma das quatro unidades morfoestruturais, definidas por Diniz et al. (2017), sendo a unidade Cinturão Orogênico Brasiliano. Esta é formada, de acordo com esses autoers, predominantemente por faixas de dobramentos do embasamento Pré-cambriano envolvidas nos eventos poliorogênicos que afetaram a Província Borborema no Proterozoico, sobretudo o ciclo Brasiliano-Panafricano, e da reativação cretácea que culminou na separação do Megacontinente Gondwana. Além disso, esta unidade também exibe alguns núcleos arqueanos.

Das sete unidades morfoesculturais apresentadas por Diniz et al. (2010), apenas duas encontram-se inseridas no Geoparque Seridó, sendo identificadas pela (i) Depressão Sertaneja e pelo (ii) Planalto da Borborema (Figura 8). A Unidade Morfoescultural Depressão Sertaneja compreende a unidade morfoescultural que contempla áreas aplainadas do Cinturão Brasiliano, com predomínio dos processos de dissecação. De acordo com Diniz et al. (2010) corresponde a extensas superfícies aplainadas onde a monotonia do relevo rebaixado só é quebrada pela ocorrência de elevações isoladas, em sua maioria constituídas por rochas mais resistentes a erosão do que as do entorno (inselbergs), como intrusões plutônicas exumadas. Já a Unidade Morfoescultural Planalto da Borborema corresponde a uma área de relevo bastante movimentado, com superfícies onduladas e inclinadas, com escarpas íngremes. As altitudes podem variar de 350 a $780 \mathrm{~m}$. Diniz et al. (2010) mostram que topo do planalto é caracterizado pela extensas áreas aplainadas marcadas por um relevo de colinas suaves. Nas áreas de ocorrência da Formação Serra do Martins, o relevo é relativamente plano e bordejado por escarpas íngremes, quase retilíneas como em chapadas sedimentares, o que permite se referir a essas áreas como verdadeiras chapadas sotopostas a maciços cristalinos. 
Figura 8 - Mapa Geomorfológico do Geoparque Seridó, com base em Diniz et al. (2017).

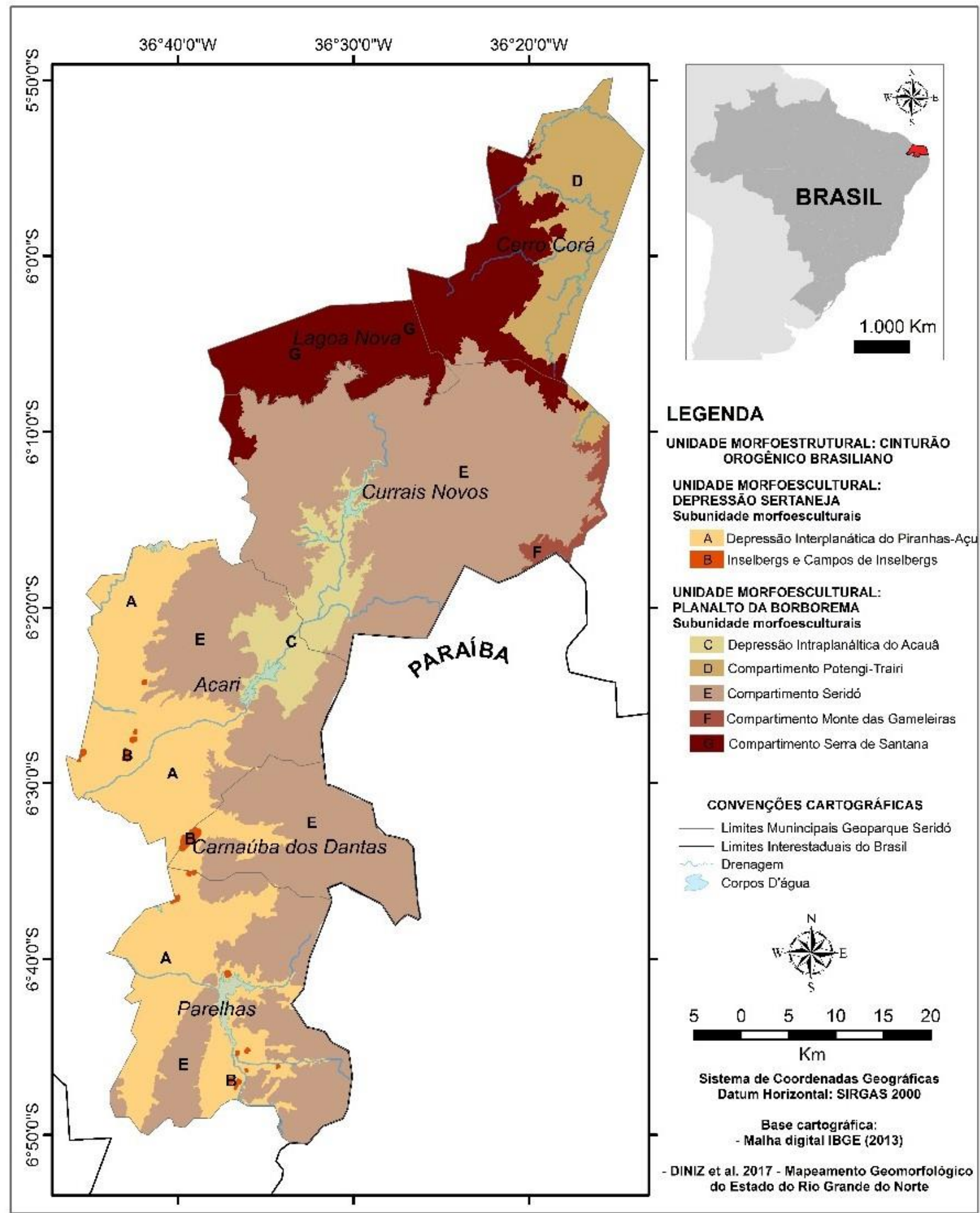

Fonte: o autor.

Como subunidades inseridas na Unidade Mofoescultural Depressão Sertaneja foram encontradas (a) Depressão Interplanática do Piranhas-Açu e (b) Inselbergs e Campos de Inselbergs; enquanto que na Unidade Morfoescultural Planalto da Borborema, as subunidades encontradas são (c) Depressão Interplanáltica do Acauã; (d) Compartimento Potengi-Trairí; 
(e) Compartimento Seridó; (f) Compartimento Monte das Gameleiras; e (g) Compartimento Serra de Santana, totalizando sete subunidades das trinta encontradas para o Estado do Rio Grande do Norte.

\section{Pareidolia identificadas no Geoparque Seridó}

Diferentes formas de relevo são facilmente encontras no território do Geoparque Seridó, com destaque para as grandes serras (de Santana, da Rajada, das Queimadas), contudo são nas menores formas que também é possível verificar feições importantes e curiosas. De acordo com Aranha e Guerra (2014) a geomorfologia tem sido cada vez mais aplicada ao planejamento da atividade turística, para que o meio físico seja mais bem aproveitado e não ocorram impactos ambientais negativos.

Borba (2016) e Borba e Meneses (2017) mostram que tais feições curiosas passam inicialmente pelo entendimento do que é Pareidolia - fenômeno psicológico que envolve um estímulo vago e aleatório, geralmente uma imagem ou som, sendo percebido como algo distinto e com significado. É comum ver imagens que parecem ter significado em nuvens, serras, montanhas e rochas, por exemplo. Para esses autores é possível verificar no relevo diferentes formas que se assemelham a algo que conhecemos, com isso ampliando o valor estético da paisagem. Assim, Borba (2016) e Borba e Meneses (2017) criaram uma metodologia de avaliação do potencial estético/turístico de geoformas por meio da percepção de sua semelhança com imagens cotidianas.

No Geoparque Seridó as diferentes rochas interagindo com as alterações climáticas, onde ações das chuvas e dos ventos esculpem o material rochoso, vem nos últimos milhares de anos produzindo formas ilusitadas que hoje servem como atrativos turísticos e educativos para os visitantes. Algumas dessas formas são vistas na Figura 9, onde a principal rocha esculpida é o granito. A Pedra do Caju (Figura 9a), incluindo a castanha, é vista junto ao Geossítio Pico do Totoró (em Currais Novos), enquanto que a Pedra do Coração está próxima ao Geossítio Açude Gargalherias (em Acari, Figura 9b). Associado ao Geossítio Serra Verde (em Cerro Corá) são encontradas várias geoformas, com destaque para as pedras Cabeça Dinossauro (Figura 9c) e do Nariz (Figura 9d). 
Figura 9 - Diferentes feições de relevo relacionadas a apofenia/pareidolia encontradas no território do Geoparque Seridó, com destaque para (a) Pedra do Caju, (b) Pedra do Coração, (c) Cabeça Dinossauro e (d) Pedra do Nariz.
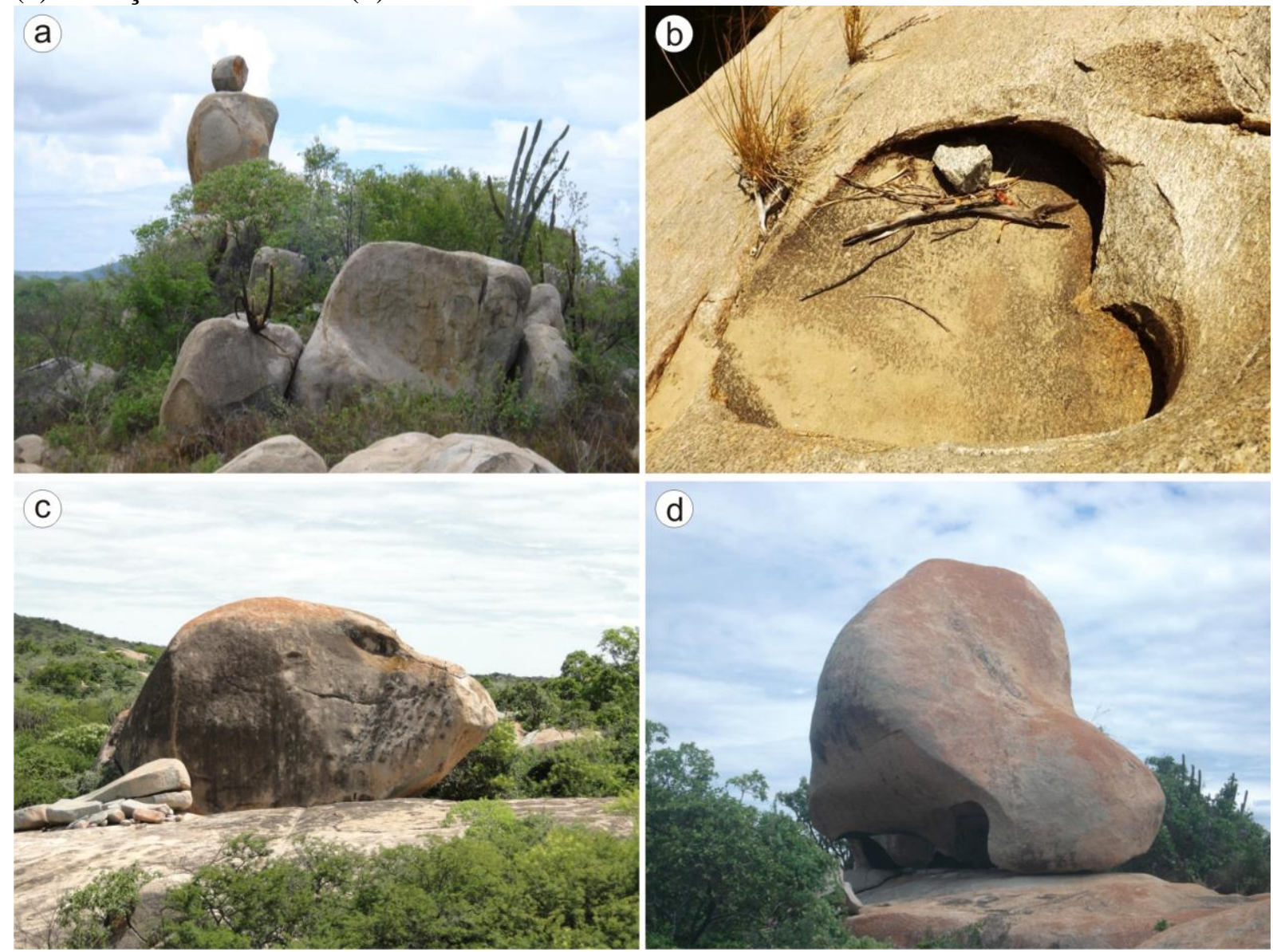

Fonte: (a) Marcos Nascimento, (b) Adriano Campelo, (c) Marcos Nascimento, (d) Marcos Nascimento.

\section{CONSIDERAÇÕES FINAIS}

Verificou-se que dos sete domínios geomorfológicos descritos para o Rio Grande do Norte como Planícies Costeiras; Vales dos rios Piranhas e Apodi; Tabuleiros Costeiros; Baixos Platôs da Bacia Potiguar; Planaltos Residuais Sertanejos; Planaltos da Borborema e Depressão Sertaneja; quase a metade (total de três) estão inseridos no território do Geoparque Seridó, são eles: (i) Planaltos Residuais Sertanejos; (ii) Planaltos da Borborema e (iii) Depressão Sertaneja.

Com relação aos dezessete padrões de relevo mapeados no Rio Grande do Norte, sete deles foram identificados no Geoparque Seridó, com destaque para (i) planaltos; (ii) chapadas e platôs; (iii) superfícies aplainadas retocadas ou degradas; (iv) inselbergs e outros relevos 
residuais; (v) domínio de colinas dissecadas e de morros baixos; (vi) domínio de morros e serras baixas; e (vii) escarpas serranas.

No que se refere ao mapeamento geomorfológico realizado no Rio Grande do Norte apenas uma das quatro unidades morfoestruturais, foi identificada no território do Geoparque Seridó, sendo descrita como Cinturão Orogênico Brasiliano. Já das sete unidades morfoesculturais, somente duas estão inseridas no geoparque, descritas como (i) Depressão Sertaneja e (ii) Planalto da Borborema. Na Depressão Sertaneja duas subunidades morfoesculturais, denominadas de (a) Depressão interplanáltica do Piranhas-Açu e (b) Inselbergs e Campos de Inselbergs, foram mapeadas. Já no Planalto da Borborema cinco subunidades morfoesculturais foram identificadas, são elas (a) Depressão Intraplanáltica do Acauã; (b) Compartimento Potengi-Trairí; (c) Compartimento Seridó; (d) Compartimento Monte das Gameleiras; e (e) Compartimento Serra de Santana.

O Rio Grande do Norte possui uma área territorial de 52.811,107 km (https://cidades.ibge.gov.br/brasil/rn/panorama), desses $2.802,504 \mathrm{~km}^{2}$ fazem parte do território do Geoparque Seridó, portanto compondo cerca de 5\% do Estado. Mesmo em uma área tão pequena fica claro que as diferentes formas de relevo encontradas mostram uma ampla diversidade. Dessa forma, o levantamento a cerca das feições geomorfológicas encontradas no território em lide faz desse um palco importante para seu uso na educação e no turismo.

\section{REFERÊNCIAS}

AB'SABER, A. N. Domínios morfoclimáticos e províncias fitogeográficas do Brasil. Orientação, São Paulo, n. 3, p. 45-48, 1969.

ARANHA, R. C.; GUERRA, A. J. T. Geografia Aplicada ao Turismo. São Paulo. Oficina de Textos, 2014.

BORBA, C. S. Geoformas: potencial estético para uso turístico na área do Projeto

Geoparque Cariri Paraibano. 98f. Trabalho de Conclusão de Curso. Departamento de Engenharia e Meio Ambiente. Bacharelado em Ecologia. Universidade Federal da Paraíba, Rio Tinto, 2016.

BORBA, C. S. e MENESES, L. F. Metodologia para avaliação do potencial estético das geoformas na área do Projeto Geoparque Cariri Paraibano. Clio Arqueológico, v.32, n.3, p.3760, 2017. 
DANTAS, M. E.; FERREIRA, R. V. Relevo. Geodiversidade do Estado do Rio Grande do Norte. PFALTZGRAFF, P. A. S.; TORRES, F. S. M. (Org.). Recife: CPRM, 2010. p.77-92, 2010.

DINIZ, M. T. M.; OLIVEIRA, G. P.; MAIA, R. P.; FERREIRA, B. Mapeamento Geomorfológico do Estado do Rio Grande do Norte. Revista Brasileira de Geomorfologia, São Paulo, v.18, n.4, p.679-701, 2017.

IBGE. Mapa geomorfológico do Brasil. Rio de Janeiro: IBGE, 1995. Escala 1:5.000.000. MEDEIROS, J.L., NASCIMENTO, M.A.L., PERINOTTO, A.R.C. Práticas turísticas por meio da análise da dimensão ambiental em geossítios do Projeto Geoparque Seridó (RN). Revista Brasileira de Ecoturismo, São Paulo, v.10, n.3, ago/out, p.552-578, 2017.

ROSS, J. L. S. Relevo brasileiro: uma nova proposta de classificação. Revista do Departamento de Geografia, São Paulo, n. 4, p.25-39, 1985.

ROSS, J. L. S. O registro cartográfico dos fatos geomorfológicos e a questão da taxonomia do relevo. Rev. do Depto. Geografia, São Paulo, v.6, n.1, p.17-29, 1992.

ROSS, J. L. S. Os fundamentos da geografia da natureza. In: ROSS, J. L. S. (Org.). Geografia do Brasil. São Paulo: EFUSP, p.13-65, 1997.

SANTOS, L. J. C.; OKA-FIORI, C.; CANALI, N. E.; FIORI, A. P.; SILVEIRA, C. T.; SILVA, J. M. F.; ROSS, J. L. S. Mapeamento Geomorfológico do estado do Paraná. Revista Brasileira de Geomorfologia, São Paulo, v.7, n.2, p.03-12, 2006. 